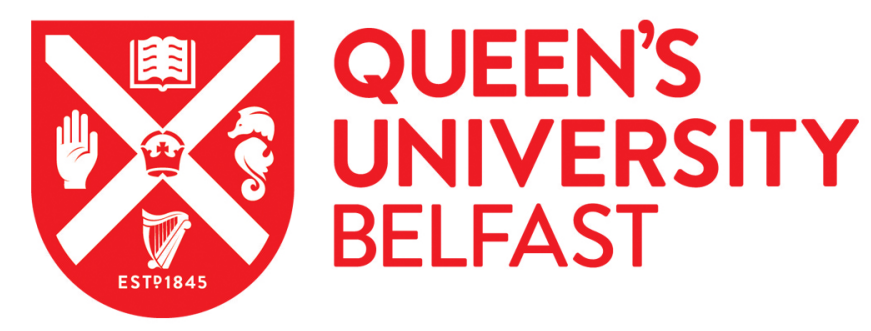

\title{
Taking Baby Steps in Molecular Logic-based Computation
}

Ling, J., Daly, B., Silverson, V. A. D., \& De Silva, A. P. (2015). Taking Baby Steps in Molecular Logic-based Computation. Chemical Communications, 51, 8403-8409. https://doi.org/10.1039/C4CC10000J

\author{
Published in: \\ Chemical Communications
}

\section{Document Version:}

Peer reviewed version

Queen's University Belfast - Research Portal:

Link to publication record in Queen's University Belfast Research Portal

Publisher rights

Copyright The Royal Society of Chemistry 2015

\section{General rights}

Copyright for the publications made accessible via the Queen's University Belfast Research Portal is retained by the author(s) and / or other copyright owners and it is a condition of accessing these publications that users recognise and abide by the legal requirements associated with these rights.

Take down policy

The Research Portal is Queen's institutional repository that provides access to Queen's research output. Every effort has been made to ensure that content in the Research Portal does not infringe any person's rights, or applicable UK laws. If you discover content in the Research Portal that you believe breaches copyright or violates any law, please contact openaccess@qub.ac.uk. 


\title{
Taking Baby Steps in Molecular Logic-based Computation
}

\author{
Jue Ling, Brian Daly, Victoria A. D. Silverson and A. Prasanna de Silva \\ Received (in $X X X, X X X) X$ th $X X X X X X X X X 200 X$, Accepted Xth $X X X X X X X X X 200 X$ \\ First published on the web $X$ th $X X X X X X X X X 200 X$ \\ ${ }_{5}$ DOI: 10.1039/b000000x
}

\begin{abstract}
Molecular logic-based computation is a broad umbrella covering molecular sensors at its simplest level and logic gate arrays involving steadily increasing levels of parallel and serial integration. The fluorescent PET(photoinduced electron 10 transfer) switching principle remains a loyal servant of this entire field. Applications arise from the convenient operation of molecular information processors in very small spaces.
\end{abstract}

\section{Introduction}

Since molecular logic-based computation arrived in the primary 15 literature, ${ }^{1}$ it has been embraced by around 250 laboratories in many different parts of the world (Figure 1). ${ }^{2}$ It has been supported by six dedicated books ${ }^{2-7}$ and by substantial chapters in several other volumes. ${ }^{8-13}$ A large number of review articles are also available, ${ }^{14-40}$ including article collections in special journal 20 issues. ${ }^{41-43}$ A series of biennial conferences dedicated to the field has completed the fourth edition. ${ }^{44}$ The first commercial product is serving worldwide in life-critical situations, ${ }^{45,46}$ with sales of

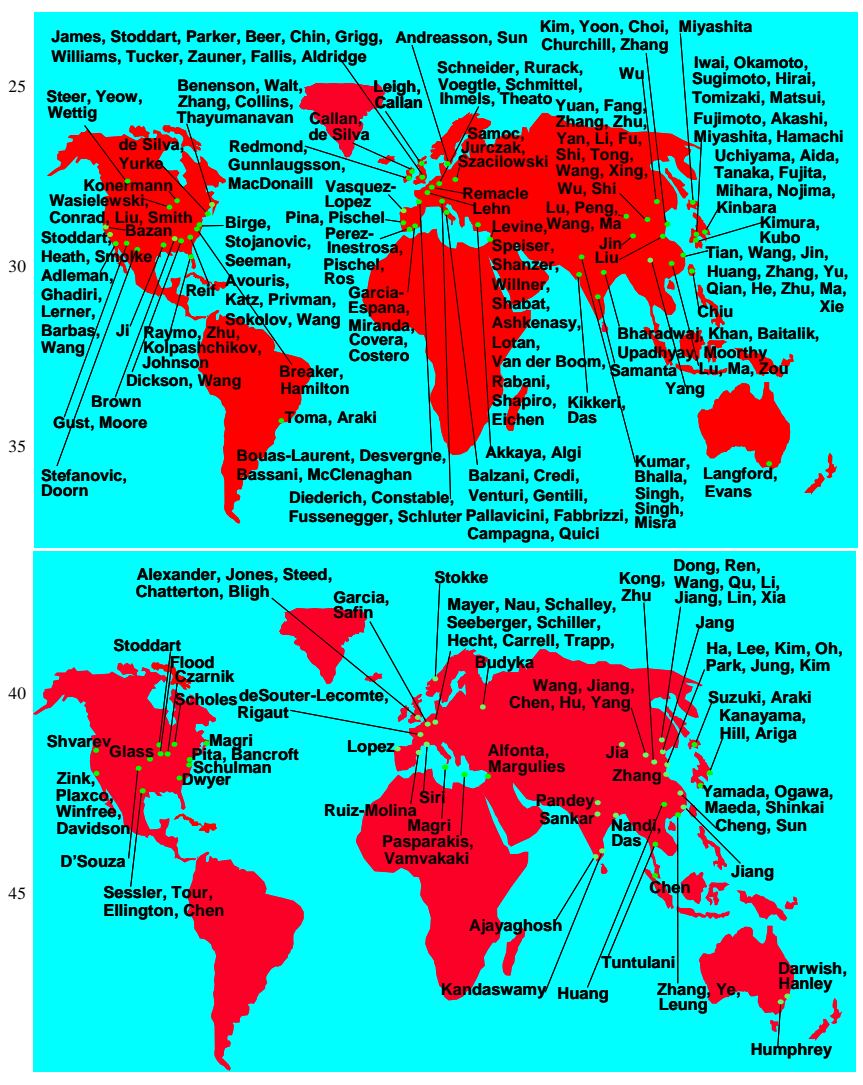

Figure 1a and 1b. Approximate world maps of the sources of molecular logic devices. Single input - single output devices have been omitted.
$120 \mathrm{M}$ \$ so far. We are grateful for this opportunity to outline the 55 journey of the field and to describe the lessons learned over the past two decades.

\section{A robust design tool for molecular switches is available}

Our story starts with the heart of plant photosynthesis photoinduced electron transfer (PET). ${ }^{47}$ Following Weller's 60 insights into intermolecular PET process, ${ }^{48}$ intramolecular 'fluorophore-spacer-receptor' systems could be developed. ${ }^{49-51}$ These have two distinct states, one where the receptor is free of the target species and another where the receptor has captured the target. Usually, the fluorescence emission of the first state is 65 switched 'off' (output 0 ) and that of the second state is switched 'on' (output 1). This is the fluorescent PET sensor/switch principle. It is Boolean single input - single output YES logic, ${ }^{2-7}$ where the fluorescence output is driven by the target species input. Similarly, single input - single output NOT logic ${ }^{2-7}$ can also 70 be arranged.

If we examine the two states a bit more closely, the excited state energy of the fluorophore is larger than the numeric sum of the oxidation and reduction potentials of the receptor and fluorophore respectively. When the receptor captured the target 75 species, the oxidation potential is raised, to the point that PET is not possible so that we have fluorescence resurrection. This photoelectro-chemical mechanism shows the modular behaviour ${ }^{52,53}$ of the 'fluorophore-spacer-receptor' system, which is molecular engineering in action. It is gratifying that such a 80 design tool with several quantitative features ${ }^{52,53}$ has been taken up by around 300 laboratories. ${ }^{2}$ A snapshot of the developments of this tool during the past year or two is contained in a recent review. ${ }^{54}$

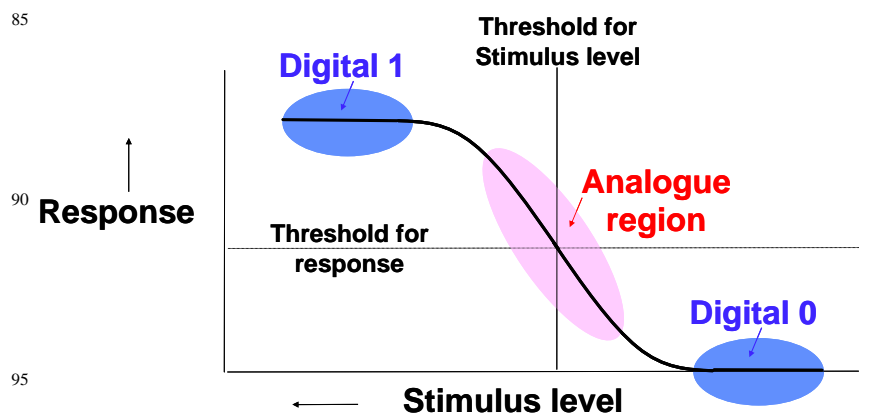

Figure 2. Stimulus-response curve for a molecular device. 100 Reprinted from ref. 2.

3. Sensors are the simplest logic gates operated in the analog regime

The 'off-on' or ' $0-1$ ' switching language of the previous section suggests binary digital molecular behaviour is being discussed. 105 Indeed, the commonest and simplest 'mass action'-type equilibria 
clearly pass a molecule between bound and free states when it is confronted with a target species. At the limits of no and excess target species, the observable properties of the system are substantially different and distinguishable so that the binary 5 digital aspect persists in the experimental output, even at the single molecule level. ${ }^{55-59}$ Additionally, many chemical tests in a clinical/commercial/managerial setting aspire to deliver a 'well/ill', 'pass/fail' or 'go/no go' decision which is binary digital anyway.

10 When the usual situation of large populations of molecules is considered, it is clear that the binary digital output is given up when the target species concentration is finite. Now the output property becomes smoothly tunable. Such a stimulus-response curve for a molecular device is shown schematically in Figure 2.

15 This is the analogue regime, which is well-known in electronics. ${ }^{60}$ Indeed, the building blocks of digital electronics, e.g. diodes, triodes and transistors have their own analogue regimes. Even molecular versions of triodes show this behaviour. ${ }^{61,62}$

20

'Off-on' sensors are YES Logic are NOT Logic superposed YES/NOT Logic
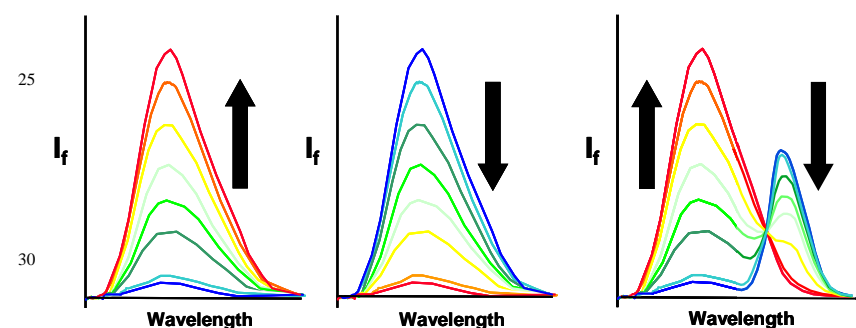

Figure 3. Schematic representation of three common fluorescence sensing scenarios, with their Boolean logical 35 designation.

The large literature on fluorescent sensing,, ${ }^{50,63-66}$ for example, has a small number of scenarios. Three of the most common of these are shown in Figure 3. The 'off-on' or 'turn on' or 'CHEF' 40 type corresponds to Boolean single input - single output YES logic. The 'on-off' or 'turn off' or 'CHEQ' type corresponds to Boolean single input - single output NOT logic. The 'wavelength shift' type corresponds to superposed YES/NOT logic. ${ }^{2}$ Superposition is a foundational concept in quantum information 45 processing. ${ }^{67}$ Overall, it is clear that most molecular sensors (fluorescent or not) have a Boolean basis, even though they are operated in an analogue fashion.

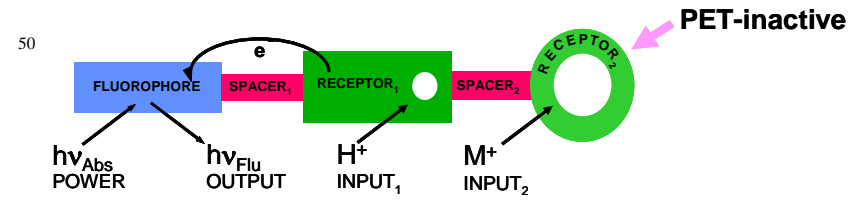

Figure 4. 'Fluorophore-spacer1-receptor1-spacer2-receptor2' system exemplified by $\mathbf{1}$.

A recent example would be in order at this point. This 60 concerns a key analogue device invented during the growth of the electronics industry - the triode. ${ }^{60}$ We arrange $^{62}$ a molecular photoionic emulation of it, similar to an all-photonic emulation presented by Gust's laboratory. ${ }^{61}$ It is well-known that fluorescent $\mathrm{pH}$ sensors possess a sigmoidal intensity-pH profile. ${ }^{68}$ ${ }_{65}$ As mentioned above, the input-output characteristic of the triode is also quasi-sigmoidal. ${ }^{60}$ However, this characteristic function is tunable with a third variable. Similar tuning of the sigmoidal intensity-pH profile can be arranged by employing a 'fluorophore-spacer 1 -receptor ${ }_{1}$-spacer ${ }_{2}$-receptor 2 ' system, ${ }^{53}$ where 70 the second receptor is not capable of engaging in any major interactions with the fluorophore (Figure 4). Now, the $\mathrm{pK}_{\mathrm{a}}$ value of the sensor becomes adjustable by electrostatic repulsion between the receptor1-bound $\mathrm{H}^{+}$and another cation held by receptor2 provided that the two receptors actions are orthogonal. 75 The amine and 15-crown-5 ether receptors in $\mathbf{1}^{38}$ satisfy this requirement. Protonation of the amine arrests PET from the amine to the anthracene fluorophore and leads to switching 'on' of fluorescence.

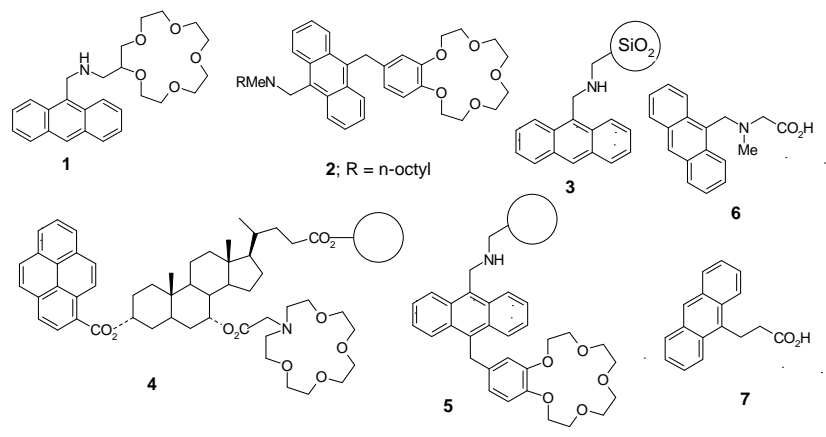

\section{4. Molecular logic gates can access very small spaces}

Most molecules found in chemical or biochemical laboratories tend to be a few nanometers or less in size. They also tend to be biocompatible in general. Once logically enabled, they can access places that far more powerful semiconductor devices cannot 85 easily operate from. A marker was put down when double input single output AND gate $\mathbf{2}$ was incorporated in an aqueous detergent micelle of ca. $3 \mathrm{~nm}$ radius. ${ }^{69}$ The amine and benzocrown receptors within 2 can each launch a PET process unless they are blocked by 'high' levels of $\mathrm{H}^{+}$and $\mathrm{Na}^{+}$ 90 respectively. Thus only the situation of 'high' $\mathrm{H}^{+}$and 'high' $\mathrm{Na}^{+}$ results in 'high' fluorescence output. More immediately useful systems covalently anchor molecular PET switching devices to micrometric polymer particles, ${ }^{70-72}$ e.g. gates $\mathbf{3}, \mathbf{4}$ and $\mathbf{5}$.

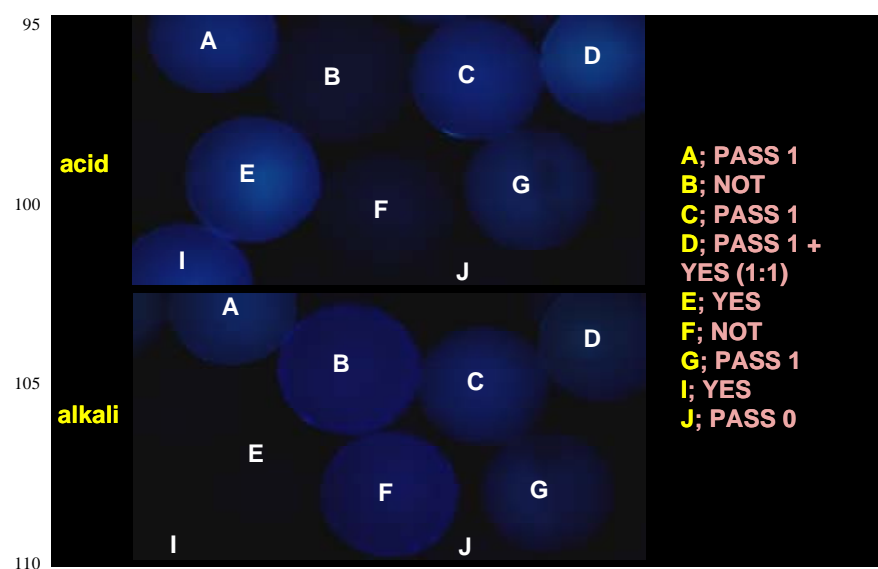

Figure 5. Fluorescence micrographs demonstrating molecular computational identification (MCID) of polymer beads. The beads are tagged with different logic gates and treated with (top) acid and (bottom) alkali in aqueous methanol $(1: 1, \mathrm{v} / \mathrm{v})$ under 115 ultraviolet $(366 \mathrm{~nm})$ irradiation. The logic gate types of some of the beads are discussed in the text. Reprinted from ref. 72. 
The problem being solved here is one of individually identifying a large number of small objects. Being submillimetric, these small objects cannot be conveniently tagged 5 with RFID chips. ${ }^{73}$ The latter, when operated with sensible electromagnetic frequencies, cannot be easily miniaturized below this size-scale. On the other hand, as shown in the previous paragraph, molecular tags can handle far smaller-sized objects. Though molecular fluorescent tags are known, the broad 10 fluorescence signatures do not permit the handling of more than a hundred objects. $^{74}$ The needs of combinatorial chemistry laboratories concern much larger numbers of objects. ${ }^{75,76}$ So we propose the use of logically-enabled molecular fluorescent tags so that each colour can produce a large diversity, each with its own 15 logic signature, e.g. $\mathrm{H}^{+}$-driven YES (6) and $\mathrm{H}^{+}$-driven PASS 1 (7). Their carboxylic acid groups are converted to peptide links during the object-tagging procedure. This is the technique of molecular computational identification (MCID). ${ }^{72}$ Both these gates 6 and 7 employ the same fluorophore with the same 20 emission and excitation profiles. Since 7 contains only the fluorophore, its emission is unaffected by $\mathrm{pH}$ and retains PASS 1 logic. Since $\mathbf{6}$ additionally contains an amine receptor, it permits PET unless blocked by the application of 'high' levels of $\mathrm{H}^{+}$. This leads to strong fluorescence only in acid solution, i.e. $\mathrm{H}^{+}$-driven

${ }_{25}$ YES logic. These logic signatures of $\mathbf{6}$ and $\mathbf{7}$ are manifested experimentally by observing the fluorescence intensities of the tagged objects with a microscope after gentle exposure to the 'high' and 'low' levels of $\mathrm{H}^{+}$(Figures $5 \mathrm{a}$ and $5 \mathrm{~b}$ respectively). The YES gate shows strong emission only in acidic solution 30 (beads $\mathrm{E}$ and I) whereas the PASS 1 gate glows constantly whatever the $\mathrm{pH}$ (beads $\mathrm{A}, \mathrm{C}$ and $\mathrm{G}$ ), i.e. the two gates are clearly distinguishable even though they are both displaying the same coloured fluorescence. At the level of this demonstration, there is some redundancy, i.e., several beads are carrying the same tag. 35
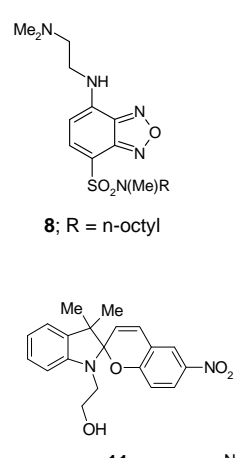

11
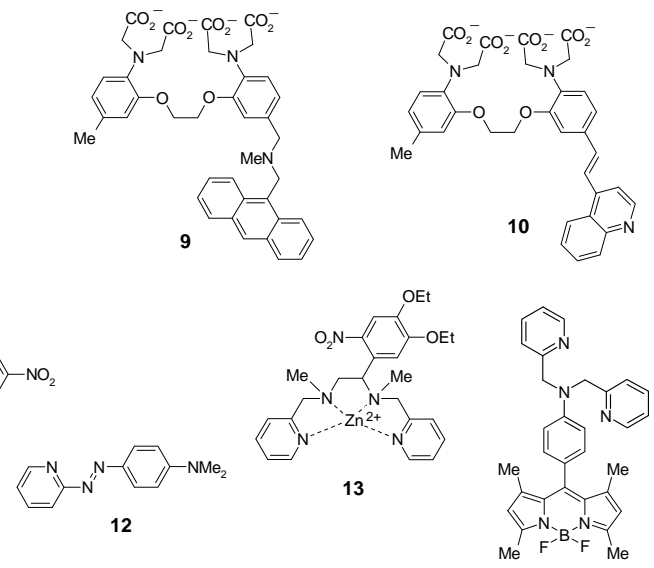

14

Figures $5 \mathrm{a}$ and $5 \mathrm{~b}$ also contain the case where one bead $\mathrm{D}$ has equimolar PASS 1 and YES logic tags attached so that the 40 summed fluorescence is seen. This produces the logic array PASS $1+$ YES (1:1) where the fluorescence intensity in acid solution is double that seen in alkaline solution. This case opens up the use of various molar ratios of a given pair of logic gates so that a series of distinguishable logic signatures will result. Such double45 tagging seriously increases the diversity addressable by this method. This also opens the door to ternary $\operatorname{logic}{ }^{77}$ which, though more information rich than binary, is not trusted in conventional computers. This is because ternary and higher logic deal with numbers which are not as different as the simple ' 0 ' and ' 1 ' of
50 binary. For instance, the numbers ' 1 ' and ' 2 ' only differ by a factor of 2. When both numbers accumulate errors of say $50 \%$, which can happen easily during long series of elementary computing steps within a conventional computer, they overlap and become indistinguishable, i.e., $1+0.5$ and $2 \pm 1 .{ }^{78}$ However, 55 our experiment involves only a few steps and the errors stay less than $10 \%$. So the numbers ' 0 ', ' 1 ' and ' 2 ' are well tolerated. de Ruiter and van der Boom also exploit this low-error situation during their use of ternary logic for data storage. ${ }^{36}$

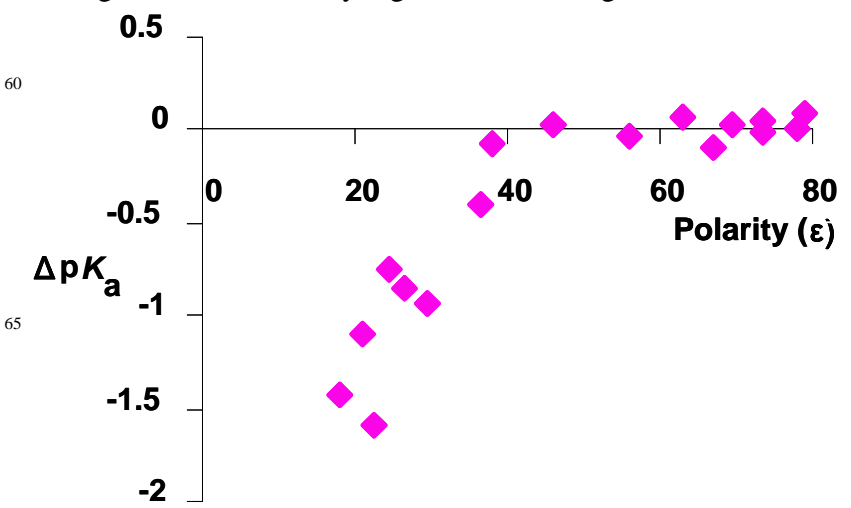

70 Figure 6. Effective local $\mathrm{H}^{+}$density (as measured by the shift of acidity constant relative to bulk water, $\Delta \mathrm{pK}_{\mathrm{a}}$ ) as a function of position of 7 (as measured by the local dielectric constant, $\varepsilon$ ) within an aqueous micelle solution of Triton X-100. Plotted from data in ref. 79.

75

Even smaller space resolution within small spaces is achievable in useful contexts. ${ }^{79}$ This involves the mapping of $\mathrm{H}^{+}$ near membranes on sub-nanometric length scales. The basic 'fluorophore-spacer-receptor' system is expanded by adding two 80 terminals which allow gross and fine positional targeting respectively. Such a molecule, e.g. 8 will take up an average position in an aqueous detergent micelle which depends on the nature of these targeting units. This position can be related to the polarity that the molecule sees, since the polarity increases 85 gradually as we move away from the micelle center along a radial line. By employing a push-pull fluorophore with substantial internal charge transfer (ICT) character in its excited state, the local polarity becomes determinable from the emission wavelength.50,65,66 Separately, the expanded 'fluorophore-spacer90 receptor' system can measure the local $\mathrm{H}^{+}$density via its emission intensity. More such local $\mathrm{H}^{+}$density-position pairs can be obtained by employing variants of $\mathbf{8}$ with other targeting groups. Thus the spatial distribution of $\mathrm{H}^{+}$in the micellar milieu is revealed (Figure 6). The $\mathrm{pK}_{\mathrm{a}}$ shift in the micellar medium 95 versus bulk water gives the local $\mathrm{H}^{+}$density (referred to that in bulk water). It is seen that the $\mathrm{H}^{+}$density decreases rapidly as we approach the micelle from bulk water.

\section{Molecular logic gate arrays of increasing complexity are accumulating}

100 The Boolean insight into the logical power of the symbols ' 0 ' and ' 1 ' 80 was developed by his followers into a family of logic operations of gradually increasing complexity. ${ }^{81-84}$ Furthermore, all-electronic semiconductor logic gates can be integrated ${ }^{85}$ serially and in parallel into arrays of dizzying complexity and 105 power which drive our current technologies. So the challenge for molecular logic-based computation is to build useful molecular logic arrays. 
Parallel integration is relatively straightforward since several gates can be present in one solution so that each gate can receive their inputs respectively. The first small-molecule half-adder was built in this way. ${ }^{86} \mathrm{H}^{+}$, $\mathrm{Ca}^{2+}$-driven AND gate 9 has a 5 fluorescence output and functions on PET principles. $\mathrm{H}^{+}, \mathrm{Ca}^{2+}$ driven XOR gate $\mathbf{1 0}$ is used in transmittance mode at a carefully selected wavelength of $390 \mathrm{~nm}$. This XOR logic action depends on the ICT (internal charge transfer) excited state of $\mathbf{1 0}$ being stabilized by bound $\mathrm{H}^{+}$and destabilized by bound $\mathrm{Ca}^{2+}$ in nearly 10 equal amounts. Though simple, this case showed that small molecules could be numerate like children by expressing the ascending number hierarchy 0,1 and 2 .

Unlike parallel integration, serial integration presents a stumbling block since most molecular logic devices use 15 distinguishable inputs and outputs. Such input - output heterogeneity prevents the output of one logic device to be passed as input into another gate. However, there are several general avenues along which progress is being made.

The commonest of these avenues is functional 20 integration. ${ }^{87}$ Instead of physically linking elementary gates, relatively complex input-output patterns are arranged within molecules outfitted with several supramolecular interactions. Several switching pathways are also allowed for. Computer science textbooks ${ }^{81-84}$ have procedures which can analyze an

25 input-output truth table according to a minimal array of elementary double input AND, double input OR and single input NOT gates.

Physical linking of simpler gates to result in more complex arrays is also possible. Light has been demonstrated

30 to serve as the linker via electronic energy transfer (EET) $)^{50,65}$ between two gates. ${ }^{88}$ When such systems are endowed with separately switchable optical properties, e.g. $\mathrm{H}^{+}$-switched photochromics, rather complex arrays of elementary gates can emerge. ${ }^{89}$ Chemical species, e.g. $\mathrm{H}^{+},{ }^{90}$ metal ions ${ }^{91}$ and ${ }^{1} \mathrm{O}_{2},{ }^{92}$

35 have also been shown to serve as the linker between gates. For instance, once switched with a dose of uv light, the photochromic $\mathbf{1 1}^{93}$ transfers a $\mathrm{H}^{+}$to $\mathbf{1 2}$. This $\mathrm{H}^{+}$transfer is signalled by a change in the uv-visible absorption spectrum of 12, which is the origin of the output(s). ${ }^{90}$ The use of $\mathrm{Zn}^{2+}$ as a 40 gate linker is illustrated by Akkaya's $\mathbf{1 3}$ and $\mathbf{1 4 .} .^{91} \mathbf{1 3}$ represents 'caged' $\mathrm{Zn}^{2+}$ which is released upon the supply of a dose of uv light absorbable by 13. Once liberated into solution, $\mathrm{Zn}^{2+}$ has the chance to bind to the receptor moiety of 14, so that its fluorescence can be switched 'on' and be 45 observed as the output.

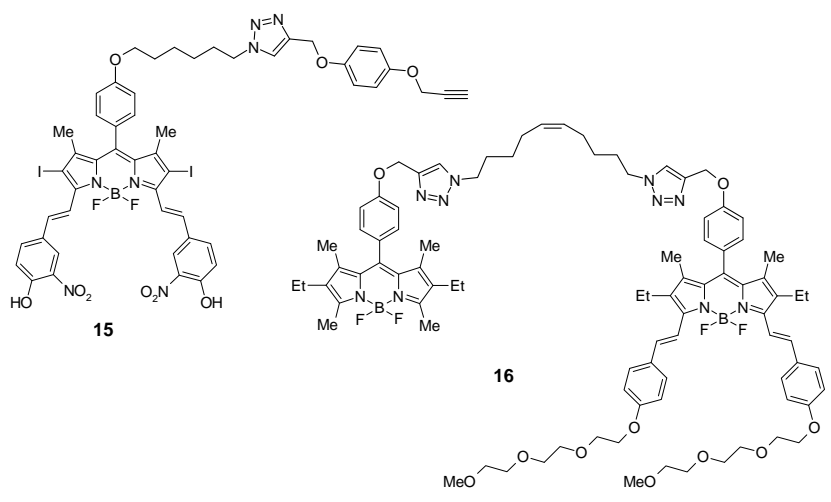

Akkaya goes further by applying a non-ionic messenger, ${ }^{1} \mathrm{O}_{2}$, 50 between gates. ${ }^{92} \mathrm{H}^{+}$, light dose-driven AND gate $\mathbf{1 5}$ produces ${ }^{1} \mathrm{O}_{2}$ as output only under acidic conditions when light of a carefully selected wavelength $(660 \mathrm{~nm})$ light is applied. 15 absorbs this light only when it is in the protonated (phenol) form but not when it is in the deprotonated (phenolate) form. Upon light absorption, 55 the lowest singlet excited state of $\mathbf{1 5}$ quickly evolves to its lowest triplet excited state owing to the heavy atom nature of the internal iodine atoms. This, in turn, transfers its energy to form ${ }^{1} \mathrm{O}_{2}$ from ubiquitous ${ }^{3} \mathrm{O}_{2}$.

The integration of gate $\mathbf{1 5}$ with gate $\mathbf{1 6}$ is facilitated by ${ }_{60}$ placing them in a soap micelle in $\mathrm{D}_{2} \mathrm{O}$ (where the lifetime of ${ }^{1} \mathrm{O}_{2}$ is extended). $\mathbf{1 6}$ contains an intramolecular pair of fluorophores so that the donor's emission at $537 \mathrm{~nm}$ is hardly seen due to EET to the acceptor. However, ${ }^{1} \mathrm{O}_{2}$ destroys the alkenic connection between the two fluorophores so that EET virtually ceases and ${ }_{65} 537 \mathrm{~nm}$ emission emerges strongly. Since glutathione would be a sacrificial protector of $\mathbf{1 6}$, we have a ${ }^{1} \mathrm{O}_{2}$, glutathione - driven INHIBIT(glutathione) gate where glutathione is the disabling input.

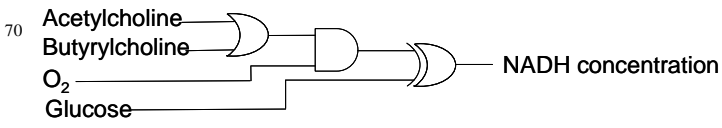

Figure 7. Enzyme-based logic array involving serial integration. ${ }_{75}$ The enzymes involved are acetylcholine esterase, choline oxidase, microperoxidase and glucose dehydrogenase.

The Krebs cycle of early biochemistry classes is a reminder to us that the product from one enzyme can serve as 80 the substrate for the next enzyme. Since enzyme-based logic is well-developed, ${ }^{30}$ this path can be used to cascade enzymes to produce biomolecular logic arrays. For example, Willner, Katz and their colleagues combine acetylcholine esterase, choline oxidase, microperoxidase and glucose dehydrogenase 85 to achieve the minimized gate array shown in Figure $7 .{ }^{94}$ The selectivity of acetylcholine esterase is not so extreme. So it hydrolyzes acetylcholine and butyrylcholine with comparable efficiency in an OR logical manner. The product, choline, is seized by the next enzyme, choline oxidase, if dioxygen is 90 supplied as the oxidant. $\mathrm{H}_{2} \mathrm{O}_{2}$ is produced from this step according to choline, $\mathrm{O}_{2}$-driven AND logic. The third enzyme, microperoxidase, uses $\mathrm{H}_{2} \mathrm{O}_{2}$ to oxidize $\mathrm{NADH}$, while the fourth enzyme, glucose dehydrogenase, processes glucose with the aid of $\mathrm{NAD}^{+}$. Another publication from the same 95 laboratory shows how a combination similar to the third and fourth enzymes leads to XOR logic behavior when the NADH concentration is monitored under certain conditions. ${ }^{95}$

The success of enzymes outlined in the previous paragraph can be emulated by oligonucleotides. DNA-based logic gate 100 arrays with serial integration depend on strand displacement by another strand with a longer run of hybridization. ${ }^{96-100}$ This depends on a duplex containing an overhang region, which can serve as a toehold for the encroaching strand. Indeed, the inputs, outputs and devices are all composed of oligonucleotides. Even 105 solid-phase versions are available. ${ }^{101}$

At a larger size-scale, cuvet arrays and microtiter plates are also playing a part in the drive towards higher serial integration of molecular gates. Raymo and Giordani ${ }^{102}$ employ photochromics in cuvet arrays and measure optical transmittance of the 110 reading light through the queue of cuvets, while dosing each cuvet independently with the writing light as inputs. Choosing such queues in 2- and 3-dimensional cuvet arrays can extend this approach further. Szacilowski ${ }^{103}$ uses environmentally-sensitive 
colour-forming reactions towards the same end via a similar tactic, but creates more complexity through the environmental variables, e.g. ion concentration, ionic strength etc. Schiller ${ }^{104}$ translates each serial connection of a chosen logic array expressed 5 exclusively in terms of IMPLICATION gates into an algorithm for pipetting input species into wells containing the molecular IMPLICATION logic device ${ }^{59}$ in a microtiter plate, while exploiting the 'universal' or 'complete' nature of the gate pair of IMPLICATION and PASS 0. The 'universal' nature of the 10 NAND or NOR gates are widely exploited in the semiconductor industry during integrated circuit manufacture. ${ }^{81,83}$

\section{Molecular logic-based computation at the human level is now possible}

A part of our (and animal) visual attention process is the rapid 15 detection of edges of approaching objects. ${ }^{105}$ This is critical for our survival and hence its presence deep within our nature. This is how we quickly judge approaching objects according to our expectation from memory so that we can make an appropriate response. Here is an experiment that the reader can do to directly

20 feel this truth. This is an experiment that many of us do often, rather inadvertently. We sit in a bus shelter waiting for the bus to come round the corner in the road some distance away. Sometimes we spot a tall profile growing around the corner within milliseconds, and our leg muscles tense and raise us off 25 the seat. This is the edge detection in our eyes and brains kickingin, concluding rapidly that the tall profile peeking round the corner matches the tall profile of a bus (as compared to the many cars on the road). But then, as more of the object emerges from round the corner, its details show that it is not the bus but only a 30 lorry. We sink into the seat again. This is the slower, but more comprehensive, computation being conducted centrally in our brains. We refer the reader to detailed psychological tests concerning objects approaching at moderate speeds, ${ }^{106}$ which confirms this analysis.

35 Edge detection is also an important activity in machine vision, as well as in image processing software. ${ }^{107}$ For instance, the Canny algorithm exploits the large gradient of light intensity at the edge. When the Canny algorithm is run on a picture, pixels are raster-scanned and central differences are taken (meaning the 40 intensity of the pixel ahead minus the intensity of the pixel behind in the horizontal line) after each pixel has been averaged in a Gaussian distribution with intensities in pixels vertically above and below. Then all pixels which display a higher central difference than a chosen threshold are declared as edge pixels. A

${ }_{45}$ further check of contiguity is applied so that isolated edge pixels are declared as 'false positive' and rejected. It is crucial to note that the Canny (and similar) algorithms require a substantial 'stored program' computer with a graphical user interface. A small-scale integrated logic gate array will not suffice. This 50 relative complexity is in keeping with the deep-seated human/animal nature of edge detection.

Amazingly, such edge detection can be arranged in genetically-engineered bacteria ${ }^{108}$ and also in reactive DNA networks. ${ }^{109}$ Still, it would be remarkable if small molecules ${ }_{55}$ devoid of any connection with life could perform the same feat. This has been achieved very recently by employing a small molecular logic system composed of a fluorescent pH 'off-on' sensor (of the YES logic type) and a photoacid generator on lightly buffered and partially dried paper. ${ }^{110}$ An object mask is 60 imaged onto the paper by means of writing $254 \mathrm{~nm}$ light. In the irradiated regions, a light dose-driven 'off-on-off' fluorescence function, with binary XOR and ternary logic characteristics, is observed. The slow diffusion of protons, to overcome the $\mathrm{pH}$ buffer just outside the irradiated regions, creates the observable
65 edge via bright fluorescence by escaping a bimolecular quencher which is the second product of the photoacid generator.

\section{Conclusions}

We have seen how simple photochemical ideas have driven an early approach to molecular logic-based computation. Some of 70 the earliest cases which can, in hindsight, be interpreted as molecular logic, are also photochemical in nature and are available from the work of Wolfbeis ${ }^{111}$ and Shinkai. ${ }^{112}$ Other photochemical approaches, e.g. those based on photochromism, ${ }^{113,114}$ are equally productive. General chemical 75 phenomena, e.g. gel swelling, ${ }^{115,116}$ also yield rich rewards. Looking even further afield, molecular biologists are converting to the Boolean logic approach ${ }^{117-119}$ from the 1994 method for exploiting parallel DNA processing to tackle hard computing problems. ${ }^{120}$ We now need the communities separately focussing 80 on oligonucleotides, enzymes and small molecules to come together and pool intellectual resources. Such a common front would provide usable insights for gene ${ }^{28}$-, cell ${ }^{108,121}$ - and DNA reaction network ${ }^{109}$-based information processing. Then the baby steps that we all have taken until now could develop into bigger 85 strides.

We are grateful to EPSRC, DEL Northern Ireland, X. G. Ling and L. H. Wang for support and help.

\section{Notes and references}

Address, School of Chemistry and Chemical Engineering, Queen's

90 University, Belfast BT9 5AG, Northern Ireland. Tel: (+)44 289097 4422;

Fax: (+)44 289097 4687; E-mail: a.desilva@qub.ac.uk

1 A. P. de Silva, H. Q. N. Gunaratne and C. P. McCoy, Nature 1993, $364,42$.

952 A. P. de Silva, Molecular Logic-based Computation, Royal Society of Chemistry, Cambridge, 2013.

3 S. Uchiyama and A. P. de Silva, Molecular Logic Gates - Functional Molecules with the Ability of Information Processing (in Japanese), Kodansha, Tokyo, 2014.

1004 Z. Q. Guo, W. H. Zhu, H. Tian and A. P. de Silva, Molecular Logicbased Computation (in Chinese), East China University of Science and Technology Press, Shanghai, 2014.

5 Molecular and Supramolecular Information Processing, (Ed: E. Katz), Wiley-VCH, Weinheim, 2012.

1056 Biomolecular Information Processing, (Ed: E. Katz), Wiley-VCH, Weinheim, 2012.

7 K. Szacilowski, Infochemistry, Wiley, Chichester, 2012.

8 Electron Transfer in Chemistry, Vol. 5 (Eds. V. Balzani, A. P. de Silva and I. R. Gould) Wiley-VCH, Weinheim, 2001.

1109 V. Balzani, A. Credi and M. Venturi, Molecular Devices and Machines. $2^{\text {nd }} E d$. VCH, Weinheim, 2008.

10 Molecular Switches. $2^{\text {nd }}$ Ed. (Eds. B. L. Feringa and W. R. Browne) Wiley-VCH, Weinheim, 2011.

11 Encyclopedia of Supramolecular Chemistry (Eds: J. L. Atwood and J. 115 W. Steed), Dekker, New York, 2004.

12 Supramolecular Chemistry: From Molecules to Nanomaterials (Eds: J. W. Steed and P. A. Gale) Wiley, Chichester, 2012.

13 Encyclopedia of Electrical and Electronics Engineering (Ed: J. Webster) Dekker, New York, 2013.

12014 F. M. Raymo, Adv. Mater. 2002, 14, 401.

15 V. Balzani, A. Credi and M. Venturi ChemPhysChem 2003, 4, 49.

16 A. P. de Silva and N. D. McClenaghan, Chem. Eur. J. 2004, 10, 574.

17 S. Istrail and E. H. Davidson, Proc. Natl. Acad. Sci. USA 2005, 102, 4954.

12518 A. P. de Silva, Y. Leydet, C. Lincheneau and N. D. McClenaghan, J. Phys. Condensed Matter 2006, 18, S1847.

19 V. Balzani, A. Credi and M. Venturi Nano Today 2007, 2, 18. 
20 R. Ballardini, P. Ceroni, A. Credi, M. T. Gandolfi, M. Maestri, M. Semeraro, M. Venturi and V. Balzani, Adv. Func. Mater. 2007, 17, 740 .

21 U. Pischel, Angew. Chem. Int. Ed. 2007, 46, 4026.

522 A. P. de Silva and S. Uchiyama, Nature Nanotechnol. 2007, 2, 399

23 A. Credi, Angew. Chem. Int. Ed. 2007, 46, 5472.

24 J. Macdonald, D. Stefanovic and M. N. Stojanovic, Sci. Am. 2008 , 299 (5), 84.

25 V. Balzani, A. Credi and M. Venturi, Chem. Eur. J. 2008, 14, 26.

1026 K. Szacilowski, Chem. Rev. 2008, 108, 3481.

27 Y. Benenson, Mol. Biosyst. 2009, 5, 675.

28 A. E. Friedland, T. K. Lu, X. Wang, D. Shi, G. Church, J. J. Collins, Science 2009, 324, 1199.

29 J. Andréasson, and U. Pischel, Chem. Soc. Rev. 2010, 39, 174.

1530 E. Katz and V. Privman, Chem. Soc. Rev. 2010, 39, 1835.

31 M. Amelia, L. Zou and A. Credi, Coord. Chem. Rev. 2010, 254, 2267.

32 U. Pischel, Aust. J. Chem. 2010, 63, 148.

33 P. Ceroni, A. Credi, M. Venturi and V. Balzani, Photochem. Photobiol. Sci. 2010, 9, 1561.

34 H. Tian, Angew. Chem. Int. Ed. 2010, 49, 4710.

35 S. Minko, E. Katz, M. Motornov, I. Tokarev and M. Pita, J. Comput. Theor. Nanosci. 2011, 8, 356.

36 G. de Ruiter and M. van der Boom, Acc. Chem. Res. 2011, 44, 563.

2537 A. P. de Silva, Chem. Asian J. 2011, 6, 750.

38 D. Gust, J. Andreasson, U. Pischel, T. A. Moore and A. L. Moore, Chem. Commun. 2012, 48, 1947.

39 U. Pischel, J. Andreasson, D. Gust and V. F. Pais, ChemPhysChem 2013, 14, 28

3040 M. N. Stojanovic, D. Stefanovic and S. Rudchenko, Acc. Chem. Res. 2014, 47, 1845.

41 Aust. J. Chem. (Ed: A. Credi) 2010, 63 (2)

42 Isr. J. Chem. (Ed: E. Katz) 2011, 51 (1).

43 J. Comput. Theor. Nanosci. (Eds: V. Privman and D. Solenov) 2011, 8 (3).

44 International Conference on Molecular Sensors and Molecular Logic Gates, Shanghai, November 2014

45 J. K. Tusa and H. He, J. Mater. Chem. 2005, 15, 2640.

46 www.optimedical.com.

4047 Electron Transfer in Chemistry, Vols. 1-5 (Ed. V. Balzani) WileyVCH, Weinheim, 2001.

48 A. Weller, Pure Appl. Chem. 1968, 16, 115.

49 A. J. Bryan, A. P. de Silva, S. A. de Silva, R. A. D. D. Rupasinghe and K. R. A. S. Sandanayake, Biosensors 1989, 4, 169.

4550 A. P. de Silva, H. Q. N. Gunaratne, T. Gunnlaugsson, A. J. M. Huxley, C. P. McCoy, J. T. Rademacher and T. E. Rice, Chem. Rev. 1997, 97, 1515.

51 A. P. de Silva and S. Uchiyama, Top. Curr. Chem. 2011, 300, 1

52 R. A. Bissell, A. P. de Silva, H. Q. N. Gunaratne, P. L. M. Lynch, G.

$50 \quad$ E. M. Maguire and K. R. A. S. Sandanayake, Chem. Soc. Rev. 1992, 21, 187

53 A. P. de Silva, T. P. Vance, M. E. S. West and G. D. Wright, Org. Biomol. Chem. 2008, 6, 2468.

54 B. Daly, J. Ling and A. P. de Silva, Chem. Soc. Rev. 2015, CS-HIG10-2014-000334.

55 S. Brasselet and W. E. Moerner, Single Molecules 2000, 1, 17.

56 L. Zang, R. C. Liu, M. W. Holman, K. T. Nguyen and D. M. Adams, J. Am. Chem. Soc. 2002, 124, 10640.

57 M. W. Holman, and D. M. Adams, ChemPhysChem 2004, 5, 1831.

6058 R. Ameloot, M. Roeffaers, M. Baruah, G. De Cremer, B. Sels, D. De Vos and J. Hofkens,_Photochem. Photobiol. Sci. 2009, 8, 453.

59 M. Elstner, K. Weisshart, K. Muillen and A. Schiller, J. Am. Chem. Soc. 2012, 134, 8098.

60 E. Hughes, Electrical Technology, 6th Ed., Longman, Burnt Mill, 1990.

61 A. E. Keirstead, J. W. Bridgewater, Y. Terazono, G. Kodis, S. Straight, P. A. Liddell, A. L. Moore, T. A. Moore and D. Gust, J. Am Chem. Soc. 2010, 132, 6588

62 A. J. M. Huxley, M. Schroeder, H. Q. N. Gunaratne and A. P. de Silva, Angew. Chem. Int. Ed. 2014, 53, 3622.

63 Chemosensors (Eds: B. H. Wang and E. V. Anslyn), Wiley, Hoboken, 2011.
64 A. P. Demchenko, Introduction to Fluorescence Sensing Springer, New York, 2009.

7565 B. Valeur and M. N. Berberan-Santos, Molecular Fluorescence. $2^{\text {nd }}$ Ed, Wiley-VCH, Weinheim, 2012.

66 J. R. Lakowicz, Principles of Fluorescence Spectroscopy. $3^{\text {rd }}$ Ed. Springer, New York, 2006.

67 M. A. Nielsen and I. L. Chuang, Quantum Computation and

80 Quantum Information Cambridge University Press, Cambridge, 2000

68 A. P. de Silva, H. Q. N. Gunaratne, P. L. M. Lynch, A. L. Patty and G. L. Spence, J. Chem. Soc. Perkin Trans. 2 1993, 1611.

69 S. Uchiyama, N. Kawai, A. P. de Silva and K. Iwai, J. Am. Chem. Soc. 2004, 126, 3032

8570 M. Ayadim, J. -L. Habib-Jiwan, A. P. de Silva and J. -P. Soumillion, Tetrahedron Lett. 1996, 37, 7039.

71 S. Nath and U. Maitra, Org. Lett. 2006, 8, 3239.

72 A. P. de Silva, M. R. James, B. O. F. McKinney, D. A. Pears and S. M. Weir, Nature Mater. 2006, 5, 787.

9073 S. Shepard, RFID: Radio Frequency Identification, McGraw-Hill, New York, 2005.

74 Smith Kline Beecham Corp. US Pat. 6,210,900 B1, 3 April 2001.

75 Combinatorial Peptide and Nonpeptide Libraries (Ed. G. Jung) VCH, Weinheim, 1996.

9576 Combinatorial Chemistry, Synthesis and Application (Eds. S. R. Wilson and A. W. Czarnik) Wiley, New York, 1997.

77 B. Hayes, Am. Sci. 2001, 89, 490.

78 R. W. Keyes, Rev. Mod. Phys. 1989, 61, 279.

79 S. Uchiyama, K. Iwai and A. P. de Silva, Angew. Chem. Int. Ed.

$00 \quad$ Engl. 2008, 47, 4667

80 G. Boole, An Investigation of the Laws of Thought Dover, New York, 1958.

81 A. P. Malvino and J. A. Brown, Digital Computer Electronics 3rd Ed. Glencoe, Lake Forest, 1993.

10582 J. R. Gregg, Ones and Zeros IEEE Press, New York, 1998.

83 A. L. Sedra and K. C. Smith, Microelectronic Circuits 5th Ed. Oxford University Press, Oxford, 2003.

84 C. Maxfield, From Bebop to Boolean Boogie Newnes, Oxford, 2009.

85 J. S. Kilby, ChemPhysChem 2001, 2, 483.

11086 A. P. de Silva and N. D. McClenaghan, J. Am. Chem. Soc. 2000, 122, 3965.

87 A. P. de Silva, I. M. Dixon, H. Q. N. Gunaratne, T. Gunnlaugsson, P. R. S. Maxwell and T. E. Rice, J. Am. Chem. Soc. 1999, 121, 1393.

88 F. Remacle, S. Speiser and R. D. Levine, J. Phys. Chem. B 2001,

115 105, 5589

89 F. M. Raymo and S. Giordani, J. Am. Chem. Soc. 2002, 124, 2004

90 S. Giordani, M. A. Cejas and F. M. Raymo, Tetrahedron 2004, 60, 10973.

91 E. T. Ecik, A. Atilgan, R. Guliyev, T. B. Uyar, A. Gumusa and E. U.

20 Akkaya, Dalton Trans. 2014, 43, 67

92 S. Erbas-Cakmak and E. U. Akkaya, Angew. Chem. Int. Ed. 2013, 52 11364.

93 F. M. Raymo and S. Giordani, J. Am. Chem. Soc. 2001, 123, 4651.

94 T. Niazov, R. Baron, E. Katz, O. Lioubashevski and I. Willner, Proc.

$125 \quad$ Natl. Acad. Sci. USA 2006, 103, 17160.

95 R. Baron, O. Lioubashevski, E. Katz, T. Niazov and I. Willner, Org. Biomol. Chem, 2006, 4, 989.

96 G. Seelig, D. Soloveichik, D. Y. Zhang and E. Winfree, Science 2006, 314, 1565 .

13097 W. Fontana, Science 2006, 314, 1552.

98 C. Zhang, J. Yang and J. Xu, Langmuir 2010, 26, 1416.

99 G. Seelig, B. Yurke and E. Winfree, J. Am. Chem. Soc. 2006, 128, 12211.

100 D. Y. Zhang and G. Seelig, Nature Chem. 2011, 3, 103.

135101 B. M. Frezza, S. L. Cockroft and M. R. Ghadiri, J. Am. Chem. Soc. 2007, 129, 14875.

102 F. M. Raymo and S. Giordani, Proc. Natl. Acad. Sci. U. S. A. 2002 99, 4941.

103 K. Szacilowski, Chem. Eur. J. 2004, 10, 2520.

140104 M. Elstner, J. Axthelm and A. Schiller, Angew. Chem. Int. Ed. 2014, 53, 7339.

105. V. Bruce, P. R. Green and M. A. Georgeson, Visual Perception $4^{\text {th }}$ Ed. Psychology Press, Hove, 2003.

106. S. H. Hock and D. F. Nichols, Atten. Percept. Psychophys. 2013, 75 145726 
107. L. G. Shapiro and G. C. Stockman, Computer Vision, Prentice-Hall, Upper Saddle River, NJ, 2001.

108. J. J. Tabor, H. M. Salis, Z. B. Simpson, A. A. Chevalier, A. Levskaya, E. M. Marcotte, C. A. Voigt and A. D. Ellington, Cell 2009, 137, 1272.

109. S. M. Chirieleison, P. B. Allen, Z. B. Simpson, A. D. Ellington and X. Chen, Nature Chem. 2013, 5, 1000.

110. J. Ling, G. W. Naren, J. Kelly, T. S. Moody and A. P. de Silva, J. Am. Chem. Soc. 2015, 137, accepted. ja-2015-006658

10111 O. S. Wolfbeis and H. Offenbacher, Monatsh. Chem. 1984, 115, 647.

112 S. Shinkai, M. Ishihara, K. Ueda and O. Manabe, J. Chem. Soc. Perkin Trans. II 1985, 511.

113 Photochromism. Molecules and Systems (Eds. H. Durr and H. BouasLaurent) Elsevier, Amsterdam, 1990.

15114 M. Irie, Chem. Rev. 2000, 100, 1685.

115 H. -J. Schneider, T. J. Liu, N. Lomadze and B. Palm, Adv. Mater. 2004, 16, 613.

116 H. Komatsu, S. Matsumoto, S. I. Tamaru, K. Kaneko, M. Ikeda and I. Hamachi, J. Am. Chem. Soc. 2009, 131, 5580.

20117 M. N. Stojanovic, D. Stefanovic and S. Rudchenko, Acc. Chem. Res. 2014, 47, 1845.

118 J. C. Cox, D. S. Cohen and A. D. Ellington, Trends Biotechnol. 1999 17, 151.

119 X. Chen and A. D. Ellington, Curr. Opin. Biotechnol. 2010, 21, 392. 25120 L. M. Adleman, Science 1994, 266, 1021.

121 M. N. Win and C. D. Smolke, Science 2008, 322, 456.

Table of Contents Graphic

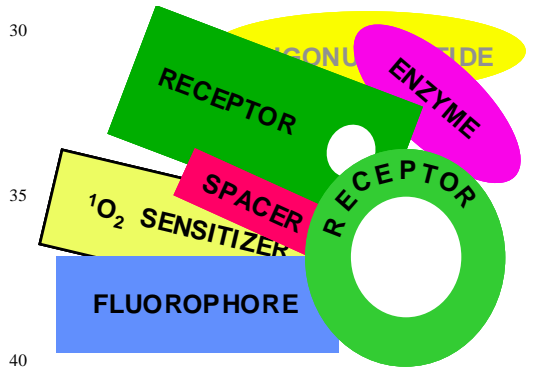

\section{Table of Contents Entry}

Constructs of fluorophores, receptors, spacers, ${ }^{1} \mathrm{O}_{2}$ sensitizers, enzymes and oligonucleotides play their part in advancing the field of molecular 45 logic-based computation.

\section{Group photograph}

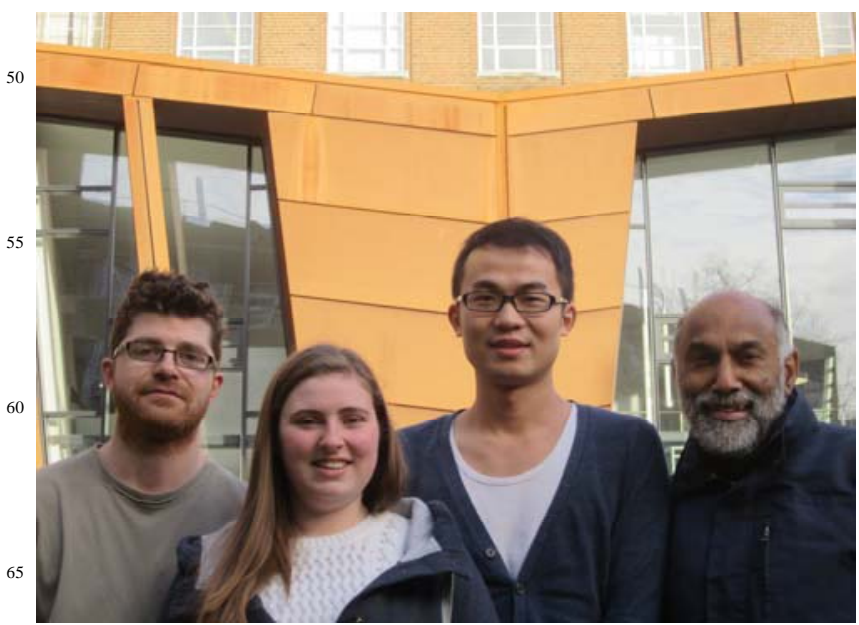

Biography

70 The authors came to study for their PhD at Queen's University

Belfast, Northern Ireland, from places as far apart as Zhenjiang,
Belfast, Carrickfergus and Colombo, Besides the chemistry day jobs, Brian (back left) brings up his two daughters, Jue (back centre) plays basketball, Victoria (front) rides her horses and AP

75 (back right) plays percussion with an Irish traditional band. 